\title{
Evidências históricas do tecnicismo em cartas sobre memórias das práticas pedagógicas na Escola Estadual Professor Anísio Teixeira (1974-1985)
}

\section{Historical evidence of technicality in letters about memories of pedagogical practices at the State School Professor Anísio Teixeira (1974-1985)}

\section{Evidencia histórica de tecnicismo en cartas sobre recuerdos de prácticas pedagógicas en la Escuela Estatal Profesor Anísio Teixeira (1974-1985)}

\author{
Costa, Antonio Max Ferreira da ${ }^{1}$ (Natal, RN, Brasil) \\ ORCID ID: https://orcid.org/0000-0002-2586-9349 \\ Nascimento, José Mateus do ${ }^{2}$ (Natal, RN, Brasil) \\ ORCID ID: https://orcid.org/0000-0003-4964-5216
}

\begin{abstract}
Resumo
O presente escrito trata-se de um recorte da dissertação de mestrado, defendida em 2017, no cerne do Programa de Pós-Graduação em Educação Profissional (PPGEP-IFRN), tendo como objetivo (re) construir parte da história das práticas pedagógicas do tecnicismo evidenciadas em cartas de memória dos diretores e professores que atuaram na Escola Estadual Professor Anísio Teixeira (1974-1985). O uso da técnica de pesquisa por meio de cartas pessoais destinadas aos diretores e professores foram utilizadas como suporte para as representações sobre as categorias: o perfil dos alunos, o currículo, os conteúdos, a metodologia de ensino, a avaliação e as festas cívicas. As reflexões dos escriturários se deu com base na Lei $N^{\circ} 5.692 / 71$ e dos teóricos da Nova História Cultural com destaque para o pensamento de Chartier (1988) sobre as representações.
\end{abstract}

Palavras-chave: História da educação. Tecnicismo. Memórias das práticas pedagógicas.

\begin{abstract}
This writing is an excerpt from the master's thesis, defended in 2017, at the heart of the Graduate Program in Professional Education (PPGEP-IFRN), aiming to (re) build part of the history of the pedagogical practices of technicality evidenced in memory letters from the principals and teachers who worked at the State School Professor Anísio Teixeira (1974-1985). The use of the research technique by means of personal letters addressed to the principals and teachers was used as support for the representations about the categories: the profile of the students, the curriculum, the contents, the teaching methodology, the evaluation and the civic parties. The reflections of the clerks were based on Law No. 5,692 / 71 and the theoreticians of the New Cultural History with emphasis on Chartier's (1988) thinking about representations.
\end{abstract}

Keywords: History of education. Technicality. Memories of pedagogical practices.

\section{Resumen}

Este escrito es un extracto de la tesis de maestría, defendida en 2017, en el corazón del Programa de Posgrado en Educación Profesional (PPGEP-IFRN), con el objetivo de (re) construir parte de la historia de las prácticas pedagógicas del tecnicismo evidenciado en cartas de memoria de los directores y maestros que trabajaron en la Escuela Estatal Profesor Anísio Teixeira (1974-1985). El uso de la técnica de investigación por medio de cartas personales dirigidas a los directores y maestros se utilizó como apoyo para las representaciones sobre las categorías: el perfil de los estudiantes, el plan de estudios,

\footnotetext{
${ }^{1}$ Docente nas redes de ensino estadual e municipal do Rio Grande do Norte. a.maxcosta@gmail.com

2 Integra o corpo docente permanente do PPGEP - Programa de Pós-Graduação em Educação Profissional do IFRN. zenmateus@gmail.com 
los contenidos, la metodología de enseñanza, la evaluación y las fiestas cívicas. Las reflexiones de los secretarios tuvieron lugar sobre la base de la Ley No 5.692 / 71 y de los teóricos de la Nueva Historia Cultural con énfasis en el pensamiento de Chartier (1988) sobre las representaciones.

Palavras-Clave: Historia de la educación. Tecnicismo. Memorias de prácticas pedagógicas.

\section{Introdução}

Esse artigo é um recorte da dissertação de mestrado em educação, defendida no ano 2017 no Programa de Pós-Graduação em Educação Profissional, Instituto Federal de Educação, Ciência e Tecnologia do Rio Grande do Norte (PPGEPIFRN). Aqui propõe-se refletir por meio de cartas de memórias sobre a história das práticas pedagógicas e das ideias do tecnicismo vivenciadas na Escola Estadual Professor Anísio Teixeira ${ }^{3}$, no recorte temporal de 1974 a 1985. O ano de 1974 apresenta-se ponto de partida porque foi o ano de inauguração da instituição lócus de pesquisa e 1985 pela efetivação da redemocratização política e revogação da obrigatoriedade da oferta de cursos técnicos profissionalizantes, sob orientação da Lei $N^{0} 7.044 / 82^{4}$.

As cartas de memórias foram ponto de ancoragem para a (re) construção das representações da história dessa instituição escolar, que ofertava ensino técnico profissionalizante de $2^{\circ}$ grau por meio de cursos Técnicos de Contabilidade e Assistente em Administração. O método de pesquisa estabeleceu-se a partir da análise documental pelas categorias: perfil dos alunos, o currículo, os conteúdos, a metodologia, a avaliação e as festas cívicas. Elementos de uma prática pedagógica que integra uma cultura escolar específica, marca do contexto histórico do tecnicismo brasileiro, no auge da ditadura militar.

A (re) construção da história das práticas pedagógicas (1974-1985) foram evidenciadas na escrita das Diretoras Maria Célia L. de A. e Evânia Maria Damásio; dos Professores Mário Sérgio, Roberto Cabral, Antônio Calazans e Jarbas Gomes. Nessa tessitura de depoimentos escritos em cartas, pode-se trazer a memória do passado para ressignificar o presente.

\footnotetext{
${ }^{3}$ Conforme o Projeto Político Pedagógico da Escola (PPP, 2015) A Instituição foi fundada com o nome de Centro de Ensino de $2^{\circ}$ Grau Professor Anísio Teixeira em 1973, tendo como preocupação exclusiva a formação técnicoprofissional e ênfase nas técnicas básicas; o saber-fazer suficiente para uma determinada profissão, sem maiores aprofundamentos no conhecimento. O seu primeiro ano de funcionamento foi no prédio do Colégio Atheneu Norteriograndense, porém, no ano seguinte, passou a funcionar à Rua Trairi.

${ }^{4}$ Lei disponível em:<http://www.planalto.gov.br/ccivil 03/leis/L7044.htm>. Acesso em 04 de jul. 2020. 
Ainda dialogou-se com a Lei № 5.692/71 e com teóricos que discutem a cultura escolar, a história das instituições e da Didática Geral, com destaque para o pensamento do francês Roger Chartier (1988), que trata das representações como instrumento de um conhecimento mediato, que faz ver um objeto ausente por meio da substituição por uma imagem, capaz de reconstituir em memória e de figurar tal como ele é. Também realizou-se a articulação das cartas com a história vivida no interior das escolas profissionalizantes, durante os anos 1970 no Brasil. Para tanto, evidenciase a teoria de compreenssão e apropriação dos discursos, isto é, a maneira como estes afetam o leitor e o conduzem a uma nova norma de compreensão de si e do mundo. (CHARTIER, 1988).

\section{Os seis elementos ou categorias (re) construídos em cartas de memórias das práticas pedagógicas}

Para a (re) construção das práticas pedagógicas tecidas nas cartas de memórias sobre o tecnicismo vivenciado na Escola Estadual Professor Anísio Teixeira (1974-1985), considerou-se a discussão sobre as representações das práticas. (CHARTIER, 1988).

\section{O perfil dos alunos}

Na concepção da Diretora Maria Célia e do Professor Mário Sérgio, a época que atuaram no Centro de Ensino de $2^{\circ}$ Grau Professor Anísio Teixeira, nos anos de 1974 e 1977, ambos classificam o perfil dos alunos a partir dos aspectos socioeconômicos, destacando que eram pessoas provenientes, em sua maioria, da classe média ${ }^{5}$, como justifica as falas que seguem: "[...] o grupo de alunos faziam parte da classe média, da cidade do Natal, e eles eram de destaque no mercado de trabalho"6. A esse respeito, a Diretora fundadora da escola escreveu:

Os estudantes do Centro de Ensino de $2^{\circ}$ Grau Professor Anísio Teixeira, eram

\footnotetext{
${ }^{5}$ Segundo os estudos desenvolvidos pelo Sociólogo britânico Goldthorpe (1987) existem três classes sociais, que são medidas através de sete categorias que consideram desde aspectos de produção até aspectos sociais. As três classes sociais segundo este Sociólogo se organizam em: a classe de serviço (proprietários, administradores, gerentes, profissionais altamente especializados e outros), a classe intermediária (empregados não-manuais, vendedores, autônomos, pequenos proprietários e outros) e a classe trabalhadora (baixa qualificação, trabalhadores manuais e do setor primário).

${ }^{6}$ Carta do Professor Mário Sérgio (2016). 
provindos tanto de escolas privadas como de públicas, mas em sua maioria pertencia à classe média, visto que se tratava de um ensino de referência em cursos técnicos profissionalizantes, e cumpria o objetivo da Lei № 5.692/71 que era preparar o aluno para o mercado de trabalho ${ }^{7}$.

A representação de alunos, apresentada pela Diretora Evânia Maria Damásio, estabelecia que além dos aspectos socioeconômicos, existem os elementos geográficos, mostrados por meio do seu discurso escrito:

O perfil dos estudantes do Anísio Teixeira conforme diagnóstico da época era, digo, advindos de várias classes sociais, predominando a classe média, residentes nos mais variados bairros de Natal e cidades circunvizinhas, como também do interior do estado 8 .

Em carta, o Professor Roberto Cabral, que atuou na instituição de ensino profissionalizante a partir do ano de 1982, diz que

\begin{abstract}
O perfil dos estudantes matriculados na Escola Anísio Teixeira consistia em pessoas das classes $\mathrm{C}$ e $\mathrm{D}$, que procuravam estabilidade em algum trabalho do setor comercial [...] Alguns estudantes de classe média matriculava-se apenas para adquirir estágios, tendo em vista que alguns tinham facilidade para conseguir o acesso ao estágio ${ }^{9}$.
\end{abstract}

Nota-se, então, que a partir dos anos de 1980, o perfil de representação de alunos ou estudantes vai se modificando historicamente. Na concepção dos Professores Antônio Calazans e de Jarbas Gomes, a representação de alunos se dá na condição de trabalhadores com jornada de trabalho diurna e tempo destinado aos estudos no noturno. Esses dois professores referem-se à condição do estudante que passava o dia inteiro trabalhando e que, no horário da noite, estudava no ensino técnico profissionalizante. As declarações confirmam a alteração do perfil socioeconômico dos alunos, que em período histórico anterior, provinham da classe social "C"10.

O Centro de Ensino de $2^{\circ}$ Grau Professor Anísio Teixeira, a princípio,

\footnotetext{
${ }^{7}$ Carta da Diretora Maria Célia L. de A. (2016).

${ }^{8}$ Carta da Diretora Evânia Maria Damásio (2016).

${ }^{9}$ Carta do Professor Roberto Cabral (2016).

10 A classe "C" é descrita nos estudos da Fundação Getúlio Vargas (FGV) como sendo a classe média brasileira, essa estratificação é implementada a partir do impacto de bens sobre medidas de acesso a bens duráveis e seu respectivo número (TV, rádio, lava-roupa, geladeira e freezer, vídeo-cassete ou DVD), banheiros, empregada doméstica, e nível de instrução do chefe de família. Texto disponível em:< http://www.cps.fgv.br/cps/classe_media/>. Acesso em 24 de nov. 2016.
} 
seguia um projeto de ensino voltado aos interesses da classe média da capital potiguar e por isso, considerado de referência, durante os anos de 1974 a 1982. Então, questiona-se: o que motivava pessoas da classe média a procurar uma escola profissionalizante para seus filhos? O que atraia esse grupo social era a propaganda do emprego imediato, o estágio em empresas e bancos, que ocorria no $3^{\circ}$ ano dos cursos técnicos profissionalizantes, etapa curricular obrigatória das habilitações ofertadas?

Durante os anos de 1983 a 1985, a escola passa a formar pessoas da classe-que-vive-do-trabalho, conforme preconizava a Lei № 5.692/71: formar o filho do trabalhador brasileiro para o mercado de trabalho, evidenciando uma dualidade educacional por consolidar a tese de que esse tipo de ensino tinha um sentido de terminalidade, como afirmam Cunha (2005) e Germano (2011).

A esse respeito, em carta, a Diretora Maria Célia diz: "Recordo-me de um estudante que vinha de uma escola privada e me disse que a mãe tinha uma loja e ele queria fazer o curso técnico em Assistente de Administração para dirigir o comércio da família, e depois ele iria para a universidade"11.

Esse discurso demonstra que o estudante descrito na fala da Diretora, que atuou em 1974, tinha duas possibilidades: a primeira, de aprender uma profissão para administrar o comércio da família e a segunda, de após conclusão do curso, dar continuidade aos estudos no ensino superior. $O$ dado exposto foge à regra geral, uma vez que esse aluno não tinha o perfil idealizado pelo projeto de ensino determinado no período dos governos do regime civil militar, que visava o fortalecimento da industrialização do Brasil, ancorado na lógica desenvolvimentista do capitalismo e na importação das ideias do capital humano de Schultz (1973). A lógica fortaleceu a máxima de que todos tem acesso ao trabalho, basta apenas que o próprio trabalhador invista na sua educação e se não o fizer, este terá que seguir as regras impostas pelo sistema, pois existe um exército de reserva de desempregados ${ }^{12}$.

\footnotetext{
${ }^{11}$ Carta da Diretora Maria Célia L. de A. (2016).

12 A denominação "exército de reserva" conforme Neto (2013, p.11) diz respeito ao que essa massa trabalhadores não-assalariados pelo capital ou por instituições acessórias e a eles disponível representa para a classe trabalhadora e para o capital. O "exército de reserva" se contrapõe à massa de trabalhadores assalariados, que é aquela parte da classe trabalhadora que está empregada pelo capital. A qualificação de "exército de reserva" é uma contraposiç̃o ao "exército ativo", ou seja, os trabalhadores assalariados são "recrutados" pelo capital ou por 


\section{O currículo}

A palavra currículo, etimologicamente, tem origem no latim curriculum que significa pista de corrida, caminho, jornada e trajetória, como afirmam Macedo (2007) e Silva (2004). Para Bobbitt (2004), currículo traduz-se como uma especificação precisa de objetivos, procedimentos e métodos para a obtenção de resultados que possam ser mensurados. O currículo relaciona-se à questão técnica, científica, de organização, planejamento, execução e avaliação dos processos de ensino e de aprendizagem. Essa concepção de currículo alinha-se ao que foi proposto para o ensino técnico profissionalizante de $2^{\circ}$ grau, empreendido nos anos de 1971 a 1985 , sendo visto como algo estático, formatado, rígido e com fins e resultados já estabelecidos, conforme propunha o mundo capitalista da época, tendo como ordem a eficácia, a eficiência e a padronização, elementos voltados para a economia liberal e o fortalecimento do modo de produção taylorista. (SILVA, 2004).

A categoria currículo, este de natureza tecnicista tem seu amparo na Lei $\mathrm{N}^{\circ}$ 5.692/71, especificamente, no artigo $4^{\circ}$ que estabelece:

Os currículos do ensino de $1^{\circ}$ e $2^{\circ}$ graus terão um núcleo comum, obrigatório em âmbito nacional, e uma parte diversificada para atender, conforme as necessidades e possibilidades concretas, as peculiaridades locais, aos planos dos estabelecimentos e às diferenças individuais dos alunos.

Sobre esse elemento, a Diretora Maria Célia e o Professor Mário Sérgio relataram que existia a parte unificada (comum) com disciplinas gerais e, depois, a parte técnica, dependendo das habilitações profissionais escolhidas (Técnico Assistente em Administração e Técnico em Contabilidade), destacando as disciplinas de Educação Moral e Cívica, OSPB, Português e Matemática, que permeavam todo o currículo dos cursos.

Essa concepção de currículo se confirma muito bem na escrita da Diretora Evânia Damásio que diz:

Quanto ao currículo era com base na Lei 5.692/71, contemplando o núcleo comum no primeiro ano, chamado unificado. $O$ segundo e o terceiro ano eram oferecidas as disciplinas técnicas especificas de cada curso (Administração,

suas instituições acessórias. Quando a acumulação de capital se acelera e o exército ativo torna-se insuficiente para tocá-la diante, o capital então "recruta" o pessoal do "exército de reserva". 
Contabilidade e Técnico em Serviços Bancários), destacando que as disciplinas de Português, Matemática, Educação Moral e Cívica, e OSPB permeavam os cursos $^{13}$.

Quanto à representação de currículo, descrita pelos Professores Roberto Cabral, Antônio Calazans e Jarbas Gomes, verifica-se que estes são unanimes em afirmar que o currículo do Centro de Ensino de $2^{\circ}$ Grau Professor Anísio Teixeira, à época, era substancialmente técnico, centrado nas habilitações profissionalizantes, que se aplicavam aos cursos de Técnico em Contabilidade e Assistente em Administração.

Observando os escritos do Professor Jarbas Gomes em relação à categoria currículo, destaca-se que era "Predominantemente técnico profissionalizante, voltado para os cursos profissionalizantes. [...] na época o currículo não tinha exigibilidade de carga horária prática, através de estágios [...]114.

Em relação ao estágio curricular, é notório nas falas que durante os anos de 1974 a 1982, o Centro de Ensino de $2^{\circ}$ Grau Professor Anísio Teixeira tinha no seu currículo a obrigatoriedade do estágio curricular, objetivando o contato direto dos alunos com o mercado de trabalho. A partir dos anos 1984 e 1985, a instituição deixa de oferecer aos estudantes os estágios obrigatórios, como mencionou o Professor Jarbas Gomes. Será que esse fato apontado pelo professor apresenta indícios da falta de interesse dos governos estaduais investirem no ensino técnico profissionalizante de $2^{\circ}$ grau, a partir desse período? No artigo $6^{\circ}$, da Lei $N^{\circ} 5.692 / 71$, tem-se:

\footnotetext{
As habilitações profissionais poderão ser realizadas em regime de cooperação com as empresas. [...] $O$ estágio não acarretará para as empresas nenhum vínculo de emprego, mesmo que se remunere o aluno estagiário, e suas obrigações serão apenas as especificadas no convênio feito com 0 estabelecimento.
}

Havia uma indicação de cooperação entre escola e empresa, com o objetivo de colocar os alunos em contato direto com as demandas do mercado de trabalho. Mesmo a Lei $N^{\circ} 5.692 / 71$ não afirmando que era obrigatório o estágio no $3^{\circ}$ ano das habilitações profissionais, as Diretoras Maria Célia e Evânia Damásio

\footnotetext{
${ }^{13}$ Carta da Diretora Evânia Maria Damásio (2016).

${ }^{14}$ Carta do Professor Jarbas Gomes (2016).
} 
mencionam que, na sua época, os estudantes faziam o estágio no comércio e nas empresas, pois elas firmavam convênios com empresas e organizações.

O currículo proposto pela Lei $N^{0} 5.692 / 71$ e mencionado pelos sujeitos da pesquisa, tem seu cerne no modelo capitalista de escola, que prioriza formar pessoas para o trabalho. Nas palavras de Bobbitt (2004), esse tipo de currículo serve para estabelecer desigualdades entre as classes sociais. Esse crítico mostra que a escolha deste ou daquele conteúdo traz implícita a ideia de homem e sociedade que se quer formar, por isso, não há currículo que seja neutro, de forma que a escolha por um modelo de currículo, pode ou não privilegiar uma determinada organização de sociedade e classe social.

\section{Os conteúdos}

As cartas elucidaram também que os agentes participantes da pesquisa concebem a representação de conteúdos como sendo conjunto de conhecimentos amparados na Lei $N^{\circ} 5.692 / 71$, guia curricular e parâmetro oficial para o $2^{\circ}$ grau da época, que definia as disciplinas para a "grade curricular", expressão atribuída ao conjunto dos componentes curriculares.

Na ótica dos teóricos da didática e das metodologias de ensino, o que são conteúdos de ensino?

Conteúdos de ensino são o conjunto de conhecimentos, habilidades, hábitos, modos valorativos e atitudinais de atuação social, organizados pedagogicamente e didaticamente, tendo em vista a assimilação ativa e aplicação pelos alunos na sua prática de vida. Englobam, portanto: conceitos, ideias, fatos, processos, princípios, leis científicas, regras, habilidades cognoscitivas, modos de atividade, métodos de compreensão e aplicação, hábitos de estudo, de trabalho e de convivência social; valores, convicções, atitudes. (LIBÂNEO, 1994, p.128).

Compreende-se, a partir de Libâneo (1994), que a definição de conteúdos de ensino é bastante complexa e que ultrapassa a ideia de um tema ou conceitos contidos em um currículo, como o reforçado pela concepção técnica apresentada na Lei № 5.692/71 e reafirmado pelos sujeitos da pesquisa. Essa representação sobre conteúdos esteve presente nas escritas dos Diretores e Professores do Centro de Ensino de $2^{\circ} \mathrm{Grau}$ Professor Anísio Teixeira:

O conteúdo da disciplina ministrado na escola era de formação profissional. Os 
alunos que buscavam o Anísio Teixeira estavam interessados em ingressar no mercado de trabalho com o Ensino Médio. Quem estudava no Anísio Teixeira tinha oportunidade de estágios em várias empresas do setor de serviços e do comércio $^{15}$.

Seguindo a mesma lógica, o Professor Roberto Cabral diz que os conteúdos focavam na relação teoria e prática. O que também afirmou o Professor Mário Sérgio: o "[...] objetivo principal era articular o conhecimento teórico-prático"16. Já nos escritos do Professor Jarbas Gomes tem-se que "os conteúdos tinham uma base teórica do que deveria aplicar no dia-a-dia das suas atividades profissionais para se ter consciência do porque estavam tomando as decisões cabíveis"17.

Percebe-se que essa concepção de conteúdos baseia-se na Lei $N^{\circ}$ 5.692/71 e é rememorada como sendo um conjunto de conhecimentos e ideias a serem transmitidas, tendo por finalidade treinar o aluno às profissões demandadas pelo mercado de trabalho, observando os princípios do capitalismo: racionalidade, eficiência e produtividade. (SAVIANI, 2013).

Então, percebe-se que ocorria a valorização desses princípios próprios do capital hegemônico na estruturação curricular dos cursos técnicos. Ideologicamente, estiveram presentes na orientação para seleção dos conteúdos ministrados no Centro de Ensino de $2^{\circ}$ Grau Professor Anísio Teixeira, buscando atender os objetivos de formar mão-de-obra especializada e barata para maximizar os lucros.

\section{A metodologia}

Sobre a categoria metodologia, destacamos a representação descrição pela diretora Maria Célia, a qual advertiu que seria um momento que envolvia teoria e prática, efetivando-se nos estágios obrigatórios ocorridos no $3^{\circ}$ ano dos Cursos Técnicos Profissionalizantes. O professor Mário Sérgio ainda idealizou a metodologia como sendo o desenvolvimento das competências, conhecimento colocado em prática, também no contexto do estágio obrigatório.

A Diretora Evânia Damásio registrou sobre metodologia do ensino técnico profissionalizante de $2^{\circ}$ grau, destacando os momentos de interlocução entre teoria e

\footnotetext{
${ }^{15}$ Carta do Professor Roberto Cabral (2016).

${ }^{16}$ Carta do Professor Mário Sérgio (2016).

17 Carta do Professor Jarbas Gomes (2016).
} 
prática, avançando ao mencionar o escritório modelo como espaço privilegiado de experiências profissionais. A sua carta explicita a escrituração que diz:

A metodologia era diversificada envolvendo teoria e prática. Para isso contávamos com laboratórios, destacando o Escritório Modelo, assim justificando o objetivo geral que era formar o aluno para o mercado de trabalho, reforçado pela oferta de estágios por bancos e empresas ${ }^{18}$.

Visualiza-se nas cartas pedagógicas que a categoria metodologia é representada pelas Diretoras Maria Célia e Evânia Damásio e pelo Professor Mário Sérgio com destaque para seus aspectos teóricos e práticos de execução dos conteúdos curriculares do Ensino Técnico Profissionalizante. Ainda, nota-se nuances dessa abordagem na voz do Professor Roberto Cabral ao referir que "A metodologia consistia em aulas expositivas, além de aulas práticas no escritório/laboratório" ${ }^{19}$. Essa representação de metodologia se complementa à concepção escrita pelo Professor Antônio Calazans "Não havia livro didático, usava-se giz e um quadronegro, em que se copiavam os textos e depois explorava" 20 .

O discurso das representações sobre metodologia de ensino, mencionada pelo Professor Antônio Calazans, se caracteriza como sendo tradicional ${ }^{21}$ conforme afirmou o Professor Jarbas Gomes de Carvalho. Então, questiona-se: o que foi a metodologia de ensino tecnicista? Seria denominado de método liberal de ensino? Como se fazia uma prática pedagógica na concepção tecnicista? De acordo com Nunes (1993)

A metodologia constitui a doutrina do método, a sua teoria. Ela discute os vários tipos particulares de métodos, organiza-os num sistema, que orienta num todo teórico o trabalho de investigação da realidade. A metodologia explica um conjunto de métodos, donde também decorre a técnica. A metodologia de ensino pode ser entendida, então, como a aplicação dos princípios gerais de uma ciência, traduzidos nos seus métodos de investigação nas situações de ensino. Concretiza-se pela aplicação dos métodos de ensino em seus pressupostos teóricos. (NUNES, 1993, p.51).

\footnotetext{
${ }^{18}$ Carta da Diretora Evânia Maria Damásio (2016).

${ }^{19}$ Carta do Professor Roberto Cabral (2016).

${ }^{20}$ Carta do Professor Antônio Calazans (2016).

${ }^{21} \mathrm{Na}$ metodologia tradicional há predominância da exposição oral dos conteúdos, seguindo uma sequência predeterminada e fixa independentemente do contexto escolar; enfatiza-se a necessidade de exercícios repetidos para garantir a memorização dos conteúdos. Os conteúdos e procedimentos didáticos não estão relacionados ao cotidiano do aluno e muito menos às realidades sociais conforme falou Cabral e Martins (2009).
} 
A metodologia de ensino e os métodos são duas faces interligadas, traduzidas como complementares e estando uma contida na outra, pois "O conceito mais simples de "método" é o caminho tomado para atingir um objetivo". (LIBÂNEO, 1994, p.150). Neste sentido, o método de ensino revela o tipo de relação estabelecida entre conteúdos; proporciona ao professor-pesquisador buscar as relações internas dos objetos de estudo, fenômeno ou problema em pauta. Nesse sentido, é pertinente compreender como as Diretoras e os Professores do Centro de Ensino de $2^{\circ} \mathrm{Grau}$ Professor Anísio Teixeira faziam para ministrar seus conteúdos e alcançar os objetivos propostos nas disciplinas. Esses sujeitos relataram nas cartas que utilizavam, predominantemente, o método da aula expositiva. Mas o que significa o método expositivo?

O método expositivo é bastante utilizado em nossas escolas, apesar das críticas que lhes são feitas, principalmente por não levar em conta o princípio da atividade do aluno. Entretanto, se for superada está limitação, é um importante meio de obter conhecimentos. A exposição lógica da matéria continua sendo, pois, um procedimento necessário, desde que o professor consiga mobilizar a atividade interna do aluno de concentrar-se e de pensar, e a combine com outros procedimentos, como no trabalho interdependente, a conversação e o trabalho em grupo. (LIBÂNEO, 1994, p.161).

Evidenciou-se que na metodologia usada no Anísio Teixeira não havia a preocupação em empregar a combinação da exposição dos conteúdos com a discussão reflexiva dos mesmos. Pelo contrário, na metodologia de ensino tecnicista, o fio condutor das práticas pedagógicas estava no condicionamento do comportamento do aluno que emitia respostas desejadas pelo professor. Segundo Luckesi (1994), no contexto do tecnicismo, a prática pedagógica é altamente controlada e dirigida pelo professor, com atividades mecanizadas, inseridas em uma proposta rígida e plenamente programada.

Percebe-se que o ensino tecnicista, empregado no Centro de Ensino de $2^{\circ}$ Grau Professor Anísio Teixeira, usava-se uma metodologia do ensino utilitarista e pragmática, cuja fundamentação tem seu advento no positivismo e no behaviorismo, que condicionava as atitudes intelectuais dos alunos.

A esse respeito, Magossi e Oliveira (2015) colocam que:

[...] a postura pragmática parece despontar como o critério mais relevante ao 
se tomar determinada decisão. É possível situar as origens do pragmatismo em um horizonte bem remoto, com o advento do empirismo filosófico, a partir do século XVI. Mas é no positivismo de Auguste Comte, na aurora do século $\mathrm{XIX}$, que o pragmatismo encontrará suas fontes e referências fundamentais. (MAGOSSI; OLIVEIRA, 2015, p.2-3).

Sobre o pragmatismo pedagógico, Saviani (2005) ressalta que na prática de ensino tecnicista, tem-se um grande valor à atividade pela atividade. Segundo Magossi e Oliveira (2015), concebe-se que:

A dimensão pragmática ganha consistência teórica na perspectiva tecnicista, a conceber o processo do ensino e aprendizagem imbuído de métodos, planejamentos, objetivos, estratégias etc., destacando os meios e os fins em educação. A dinâmica educacional deve, então, utilizar os meios mais adequados do ponto de vista meramente pragmático para alcançar os fins previamente definidos. A clareza dos fins - os objetivos - desponta como um elemento motivador para o envolvimento do aluno no processo educacional. A educação passa a contar com metas, que devem ser claras e precisas. Como em uma linha de produção, o pragmatismo tecnicista vislumbra treinar o aluno, capacitando-o com uma série de habilidades fundamentais, para a vida produtiva. (MAGOSSI; OLIVEIRA, 2015, p.3).

Será que essa vida produtiva articula os saberes teóricos e práticos da vida social e escolar? Ou só se valoriza os aspectos da vida produtiva? Seguindo as análises dos escriturários, nota-se que havia na metodologia e nas técnicas de ensino empregadas no Anísio Teixeira, uma noção de obediência e submissão, desvinculadas das questões da vida prática, ou seja, não havia a ideia de um saber fazer, articulando os conhecimentos teóricos com os práticos, pois se o fosse, o ensino tecnicista teria sido idealizado a partir da conexão entre os saberes científicos, técnicos e humanísticos adequados a capacitar para atuar nas indústrias, comércios e empresas.

Essa instrumentalização pragmática e utilitarista reduz o aluno a ser reprodutor de técnicas instrumentais, fragmentadas, reducionistas, uma espécie de máquina condicionada a atitudes, contextualizado pela lógica da ação-reação, fruto da teoria behaviorista de Skinner (1972), totalmente desprovido de uma consciência crítica e problematizadora.

\section{A avaliação}

A categoria avaliação foi pensada e representada pelos sujeitos pesquisados, como sendo um processo de verificação dos conhecimentos por meio de técnicas e de instrumentos como as provas orais e escritas, os trabalhos, os testes, 
os estágios, a participação em atividades na sala de aula e nos eventos da escola.

A Diretora Maria Célia escreveu que "A avaliação era escrita ou oral, dependendo da oferta do professor"22. A mesma ainda destacou:

No $3^{\circ}$ ano de cada curso os alunos eram avaliados pelo supervisor no campo de estágio. O supervisor deveria ser alguém que fizesse parte do local de trabalho e deveria avaliar o estagiário através de um relatório contemplando aspectos como: frequência, pontualidade e habilidades técnicas ${ }^{23}$.

Essa avaliação que também ocorria no campo de estágio, só é mencionada por Maria Célia. Será que na época dos outros sujeitos pesquisados não havia esse tipo de avaliação, durante o período de 1977 a 1985? Para o Professor Roberto Cabral "A avaliação era de caráter somativo, através de provas e trabalhos bimestrais. Levava-se em conta também a participação do aluno para o computo da nota final"24.

Compreende-se, a partir dos fragmentos postos pelos sujeitos da pesquisa, que a avaliação realizada no contexto das práticas pedagógicas do Ensino Técnico Profissionalizante de $2^{\circ}$ Grau do Anísio Teixeira fundamentava-se, primordialmente, em classificar o aluno, seguindo o nível de aprovação expresso em notas e num produto final. (DINIZ, 1982).

A esse respeito, a Lei $N^{0} 5.692 / 71$, no artigo $14, \S 1^{\circ}$ adverte:

\begin{abstract}
- A verificação do rendimento escolar ficará, na forma regimental, a cargo dos estabelecimentos, compreendendo a avaliação do aproveitamento e a apuração da assiduidade. - Na avaliação do aproveitamento, a ser expressa em notas ou menções, preponderarão os aspectos qualitativos sobre os quantitativos e os resultados obtidos durante o período letivo sobre os da prova final, caso esta seja exigida.
\end{abstract}

Como se pode visualizar, no contexto da Lei $N^{0} 5.692 / 71$, a avaliação se daria por meio do aproveitamento e pela apuração da assiduidade. A questão da avaliação como verificação do rendimento do estudante era basicamente formada por dois itens, medidos simultaneamente: assiduidade e aproveitamento.

Parafraseando Libâneo (1994), a avaliação como verificação é uma tarefa do processo avaliativo, portanto, a verificação significa a pesquisa de dados acerca

\footnotetext{
22 Carta da Diretora Maria Célia L. de A. (2016).

23 Carta da Diretora Maria Célia L. de A. (2016).

${ }^{24}$ Carta do Professor Roberto Cabral (2016).
} 
do aproveitamento dos alunos, através de provas, exercícios e tarefas ou de meios alternativos como observação de desempenho, por exemplo.

Na perspectiva de Libâneo (1994), é possível advertir que a avaliação representada pelas Diretoras Maria Célia, Evânia Damásio e pelos Professores Roberto Cabral, Antônio Calazans e Jarbas Gomes, consiste num tipo de prática avaliativa restrita ao ato de aplicar provas, sejam elas, orais ou escritas e, além disso, atribuir notas e classificar os alunos. Desse modo, nota-se que "o professor reduz a avaliação à cobrança daquilo que o aluno memorizou e usa a nota somente como instrumento de controle". (LIBÂNEO, 1994, p.198).

Percebe-se que, no contexto do Ensino Técnico Profissionalizante do Centro de Ensino de $2^{\circ}$ Grau Professor Anísio Teixeira, a avaliação não se apoia apenas na figura do professor e nem do aluno, mas na organização racional dos meios, assegurando a produtividade do processo por intermédio do planejamento e do controle, como adverte Behrens (2005). Esse tipo de educação volta-se para os princípios da eficácia e produtividade coletiva, a partir de um treinamento que castiga ao que não produz, o excluindo do sistema. Logo, é possível reafirmar que no tecnicismo o pressuposto avaliativo prioriza os meios técnicos e a ênfase se dá no fazer, como estabelece Shudo (2007).

Pensando a avaliação, na perspectiva de Hoffman (1993), pode-se afirmar que avaliação é um processo, cujo objetivo fundamental é a aprendizagem, mas como essa aprendizagem é avaliada? O que se considera nela? É a nota e os conteúdos que o aluno não aprendeu? Instigados pelas ideias de Hoffman (1993), permite-se dizer que a avaliação é uma reflexão permanente sobre a realidade, o acompanhamento, passo a passo do aluno, na sua trajetória de construção de conhecimento e não apenas um momento de verificação e de classificação do que foi aprendido ao longo do treinamento, como se fazia no Ensino Técnico Profissionalizante de $2^{\circ}$ grau.

O ato de avaliar, como defende Luckesi (1994), é um ato amoroso, no sentido de que é por meio dele que o professor acolhe, integra e inclui o aluno no contexto do ensino e da aprendizagem. Por isso, entende-se que a avaliação, nessa lógica de pensamento, não está no fim do processo de ensino e aprendizagem, nem 
no seu resultado, selecionando os mais capacitados tecnicamente. Nessa perspectiva avaliativa, Cavalcanti Neto e Aquino (2009) revelam que, apesar das contradições inerentes às escolas tecnicistas:

[...] o sujeito aprende, se forma, se constrói porque a avaliação está no interior do ato educativo, é ela que garante que o processo de aprender se efetive e é esse processo que torna o aluno sujeito na "feitura" de si mesmo. Para isso, é necessário entender a avaliação como possibilidade de vir a ser ou fazer um outro de si mesmo, a construção de cada um e do coletivo como diferentes, saudáveis, alegres, cidadãos. É a prática da nossa existência se construindo com base na avaliação que fazemos de nós mesmos e das incorporações que fazemos a partir da percepção-atuação do outro conosco, de tal forma assim como sofremos a interferência do outro, também interferimos na realidade do outro. Portanto, a formação da identidade se dá no encontro com o outro, numa construção social, e não como algo meramente objetivo e natural. O caráter da avaliação tem, assim, outra dimensão. É diferente, pois propicia avanço, progressão, mudança e a criação do novo. (CAVALCANTI NETO; AQUINO, 2009, p. 229-230).

Observa-se que a avaliação no Ensino Técnico Profissionalizante era, basicamente, constituída de provas e exames, sendo a ação do professor limitada a transmitir e corrigir os conteúdos repassados, desenvolvendo assim, momentos estanques sem nexos de conexões em termos de construção de saberes.

Ao contrário, a avaliação deveria ser um processo abrangente da existência humana que implica reflexão sobre a prática, no sentido de diagnosticar seus avanços e dificuldades. A partir dos resultados obtidos, planejar tomadas de decisão sobre as atividades didáticas posteriores, como afirma Vasconcelos (1998). A avaliação deveria acompanhar o aluno em seu processo de crescimento, facilitando a aprendizagem, desconstruindo o paradigma das práticas avaliativas conservadoras.

\section{Festas cívicas}

Nos relatos escritos nas cartas, visualizou-se que apenas as Diretoras Maria Célia e Evânia Damásio e o Professor Jarbas Gomes rememoram as festas e eventos ocorridos no Centro de Ensino de $2^{\circ}$ Grau Professor Anísio Teixeira. Elas representaram essa categoria como sendo comemorações culturais em que se homenageavam a pátria, as datas comemorativas e a cultura.

A Diretora Maria Célia em sua fala detalha que:

Quanto aos eventos, incentivávamos a participação ativa dos estudantes: 
desfile cívico de 7 de setembro, hasteamento da bandeira do Brasil e canto do Hino Nacional, uma vez por mês, no pátio interno da escola. Festejávamos o folclore, destacando a religiosidade, a cultura-brincadeiras, jogos, danças, parlendas, comidas típicas, literatura, música. Era um grande evento e contávamos com a participação de todos - alunos, professores e as famílias dos nossos estudantes ${ }^{25}$.

Além desses festejos e eventos tecidos pela Diretora Maria Célia, a Diretora Evânia Damásio, que atuou no Anísio Teixeira em 1982, comentou: "Os eventos eram realizados de acordo com o calendário, tais como: Páscoa, São João, dia do estudante que era uma tarde na praça, dia do professor, desfile cívico, festa de formatura" 26 . A fala da Diretora Evânia Maria Damásio demonstra como os eventos eram usados tradicionalmente na cultura escolar, a fim de exaltar os valores pátrios e o contexto sócio-político da época.

As datas cívicas e o hasteamento da bandeira do Brasil, bem como, o canto ao hino nacional eram marcas fortes do turno matutino e vespertino, diz-se isso, porque na escrituração do Professor Jarbas Gomes, ele destacou: "Não existia comemorações cívicas à noite, apenas datas comemorativas: dia do professor, do aluno, natal e juninas"27.

Essa categoria analisada pelo viés das representações, no contexto das práticas pedagógicas dessas Diretoras e do Professor Jarbas Gomes, do Centro de Ensino de $2^{\circ}$ Grau Professor Anísio Teixeira (1974-1985), segue as indicações da história das instituições, com destaque para "[...] a instituição escolar considerada na sua materialidade e nos vários aspectos: [...] os eventos: festas, exposições, desfiles". (NOSELLA; BUFFA, 2010, p.16). Os eventos cívicos e o culto aos símbolos nacionais da pátria brasileira, no tempo da ditadura civil militar, nas palavras de Dominique Julia "[...] trata-se de forjar uma nova consciência cívica por meio da cultura nacional e por meio da inculcação de saberes associados à noção de progresso". (JULIA, 2001, p. 23).

Recorda-se aqui que, em conversa antes da escrita da carta, a Diretora Maria Célia contextualizou os eventos cívicos, principalmente o desfile do dia 07 de setembro, no qual, os alunos se apresentam na praça cívica para as autoridades

\footnotetext{
${ }^{25}$ Carta da Diretora Maria Célia L. de A. (2016).

${ }^{26}$ Carta da Diretora Evânia Maria Damásio (2016).

27 Carta do Professor Jarbas Gomes (2016).
} 
políticas e militares com honra à pátria brasileira. Ela fez uma ligação do momento à ditadura civil militar, verbalizando que todos participavam, era uma espécie de honra e prestígio. Será que esse fato, de todos participarem e perceberem esse momento solene, não seria um momento obrigatório, semelhante a imposição do currículo com as disciplinas de Educação Moral e Cívica e OSPB?

Viñao Frago (1995) estabelece discussão sobre a cultura escolar, recobrindo as diferentes manifestações das práticas instauradas no interior das escolas, trânsito de alunos e professores, de normas e teorias. $O$ autor no exercício da conceituação engloba tudo o que acontece no interior da escola e na interpretação realizadas por seus agentes.

Sabendo que a cultura escolar envolve o conjunto de práticas, normas e teorias realizadas pelos sujeitos no interior das instituições escolares, é que se expõe na escrita pedagógica da Diretora Evânia Damásio. Antes da escrituração da carta, a mesma rememora o evento "uma tarde na praça". Conforme Evânia Damásio, esse momento acontecia na semana do estudante, culminando no dia 11 de agosto. Os alunos eram levados à Praça Cívica (Praça Pedro Velho), onde assistiam a shows musicais, saraus literários, exposições de artes, concursos de danças e gincanas culturais. "Era uma verdadeira celebração à cultura", finaliza.

A fala da Diretora Evânia Maria Damásio exalta a cultura por meio dos eventos e constitui, como adverte Silva (2009), um fato social, histórico e político, constituindo-se espaço de celebração, da brincadeira, dos jogos, da música e da dança. O olhar histórico no contexto escolar, por meio das festas e dos eventos, possibilita a reconstrução do passado, pelas interpretações, explicações e entendimento da cultura escolar de uma instituição que tinha por essência a profissionalização e o tecnicismo.

\section{Considerações Finais}

As cartas-memoriais que contaram a história das práticas pedagógicas, escritas pelos agentes que fizeram ou fazem parte da Escola Estadual Professor Anísio Teixeira, antigo Centro de Ensino de $2^{\circ}$ Grau Professor Anísio Teixeira, se aproximam do ideário da Lei $n^{\circ} 5.692 / 71$, que reformou o Ensino de $2^{\circ}$ Grau no Brasil, 
conforme o pensamento pedagógico tecnicista.

A pesquisa mostrou que a teoria do Ensino Técnico Profissionalizante e do tecnicismo foram evidenciadas nas vozes dos professores participantes ao abordarem as categoriais: perfil dos alunos, o currículo, os conteúdos, a metodologia de ensino, a avaliação e as festas cívicas. Notou-se que a Escola Estadual Professor Anísio Teixeira estava imersa no contexto da ditadura militar (1974-1985), da política desenvolvimentista, influenciada a valorizar práticas educativas que visavam o treinamento dos estudantes, para assim assumir possíveis postos de trabalho.

Percebeu-se que o currículo dessa escola foi estruturado com fins a atender aos interesses do capital, do mercado de trabalho, principalmente, dos bancos e empresas multinacionais. O modelo de currículo implantado, na maioria das vezes, tinha a intenção de sobrepor teoria e prática, mas não ocorrendo a integralidade entre as dimensões, uma vez que existia um pragmatismo utilitarista, com o objetivo de treinar o aluno para desenvolver atividades imediatas, sendo eficaz e eficiente. Logo, não havia espaço para uma formação técnica, científica e humana sob os moldes da formação humana integral. Apesar dos documentos, inclusive a legislação educacional, anunciar esse objetivo.

Verificou-se em relação à categoria avaliação do ensino e da aprendizagem, que foram empreendidos os moldes tradicionais de pedagogia para a efetivação da classificação dos alunos por meio de provas, exames e testes, pela memorização de grande número de conteúdos. Em relação às festas cívicas, a investigação demonstrou que eram realizados cultos aos símbolos da pátria e celebração a datas comemorativas como 7 de setembro e descobrimento do Brasil.

\section{Referências Bibliográficas}

BEHRENS, Marilda Aparecida. O Paradigma emergente e a prática pedagógica. 4 . ed. Curitiba, PR: Editora Universitária Champagnat, 2005.

BOBBITT, John Franklin. O currículo. Lisboa: Didática, 2004.

BRASIL. Lei n. 5.692, de 11 de Agosto de 1971. Diretrizes e Bases da Educação Nacional. Diário Oficial da República Federativa do Brasil. Brasília, 1971. Disponível em:<http://www.planalto.gov.br/ccivil_03/leis/15692.htm>. Acesso em: 24 de mai. 2015 . 
CAVALCANTI NETO, Ana Lúcia Gomes; AQUINO, Josefa de Lima Fernandes. A avaliação da aprendizagem como um ato amoroso: o que o professor pratica?. Educação em Revista, Belo Horizonte, v. 25, n. 2, p. 223-240, ago. 2009. Disponível em: <http://www.scielo.br/scielo.php?script=sci_arttext\&pid=S0102$46982009000200010 \&$ Ing=en\&nrm=iso>. Acesso em: 30 jan. 2017.

CHARTIER, Roger. A história cultural entre práticas e representações. Tradução de Maria Manuela Galhardo. Lisboa: Difusão Editora, 1988.

CUNHA, Luiz Antônio. O ensino profissional na irradiação do industrialismo. São Paulo: Unesp, 2005.

FRAGO, Antonio Viñao. Historia de la educación e historia cultural. Revista Brasileira de Educação, São Paulo, n.0, p.63-82, set./dez. 1995.

GERMANO, José Willington. Estado militar e educação no brasil (1964-1985). 5. ed. São Paulo: Cortez, 2011.

GOLDTHORPE, J. Social Mobility and class structure in modern Britain. Oxford: Claredon Press, 1987.

HOFFMANN, Jussara. Avaliação mediadora: uma prática em construção da préescola à universidade. Porto Alegre: Mediação, 1993.

JULIA, Dominique. A cultura escolar como objeto histórico. Revista Brasileira de História da Educação, Campinas, n.1, p.09-43, jan./jun. 2001.

LIBÂNEO, José Carlos. Didática. São Paulo: Cortez, 1994.

LUCKESI, C. C. Filosofia da educação. São Paulo: Cortez Editora, 1994.

MACEDO, Roberto Sidnei. Currículo: campo, conceito e pesquisa. Petrópolis, RJ: Vozes, 2007.

MAGOSSI, José Carlos; OLIVEIRA, Adelino Francisco de. Perspectivas metodológicas para o ensino de matemática: para além da racionalidade instrumental. III Simposio Internacional de Inovação em Educação 2015. Disponível em:< http://www.lantec.fe.unicamp.br/inova2015/images/trabalhos/artigos/T7.pdf>. Acesso em: 27 de jan. 2017.

NETO, Nelson Nei Granato. Exército industrial de reserva: conceito e mensuração. 2013. 126f. Dissertação (Mestrado em Desenvolvimento Econômico) - Universidade Federal do Paraná. Setor de Ciências Sociais Aplicada. Programa de Pós-graduação em Desenvolvimento Econômico, Curitiba, 2013.

NOSELLA, Paolo; BUFFA, Ester. Instituições escolares: por que e como pesquisar. Campinas-SP: Alínea, 2010. 
NUNES, Marisa Fernandes. As metodologias de ensino e o processo de conhecimento científico. Educar em Revista, Curitiba, n. 9, p. 49-58, Dez. 1993. Disponível em: <http://www.scielo.br/scielo.php?script=sci_arttext\&pid=S010440601993000100008\&Ing=en\&nrm=iso>. Acesso em: 05 dez. 2016.

PROJETO Político Pedagógico da Escola Estadual Professor Anísio Teixeira. Natal: SEECD, 2015. (Digitado).

SAVIANI, Dermeval. História das ideias pedagógicas no Brasil. 3. ed. CampinasSP: Autores Associados, 2010.

As concepções pedagógicas na história da educação brasileira. Campinas, 2005.2 Disponível em: $<$ http://www.histedbr.fe.unicamp.br/navegando/artigos_pdf/Dermeval_Saviani_artigo. pdf>. Acesso em: 19 de mar. 2016.

SCHULTZ, T. O capital humano: investimento em educação e pesquisa. Tradução de Marco Aurélio de M. Matos. Rio de Janeiro: Zahar, 1973, p.31-52.

SHUDO, Regina. Sala de aula e avaliação: caminhos e desafios. Disponível em: $<$ http://www.educacional.com.br/articulistas/outrosEducacao_artigo.asp?artigo=regin a0001>. Acesso em: 09 de nov. 2016.

SILVA, Lenina L. S., GERMANO, José W. et. al, In: Seabra, G. F.; Mendonça, I. T. L. Educação ambiental para a sociedade sustentável e saúde global. $2^{\mathrm{a}}$ edição. João Pessoa: Editora Universitária da UFPB, 2009. Vol. III.

SILVA, Tomaz Tadeu da. Documentos de identidade: uma introdução às teorias do currículo. $2^{\mathrm{a}}$ ed. Belo Horizonte: Autêntica, 2004.

SKINNER, Burrrhus Frederic. Tecnologia do ensino. Tradução de Rodolpho Azzi. São Paulo: Herder, Ed. da Universidade São Paulo, 1972.

VASCONCELOS, Celso dos Santos. Avaliação da aprendizagem: práticas de mudanças. São Paulo: Libertad - Centro de Formações e Assessoria Pedagogia, 1998. 


\section{Antonio Max Ferreira da Costa}

Natal, RN, Brasil

Doutorando em Educação pelo Programa de Pós-Graduação em Educação Profissional (PPGEPIFRN-2019); Mestre em Educação pelo Programa de Pós-Graduação em Educação Profissional (PPGEP/IFRN-2015-2017); Docente nas redes de ensino estadual e municipal, com experiência no Ensino Fundamental $\left(1^{\circ}\right.$ ao $\left.9^{\circ}\right)$, Ensino Médio e Superior. Vinculado ao NUPED (Núcleo de Pesquisa em Educação) do IFRN.

Email: a.maxcosta@gmail.com

Link do Lattes: http://lattes.cnpq.br/6446532208962557

\section{José Mateus do Nascimento}

Natal, RN, Brasil

Doutorado em Educação pela Universidade Federal do Rio Grande do Norte (2006); Tem experiência na área de Educação, com ênfase em História da Educação, História Social da Infância e passa a atuar em pesquisas relacionadas à História da Educação Profissional no NUPED (Núcleo de Pesquisa em Educação) do IFRN - Campus Natal Central; Integra o corpo docente permanente do PPGEP Programa de Pós-Graduação em Educação Profissional do IFRN

Email: zenmateus@gmail.com

Link do Lattes: http://lattes.cnpq.br/9176401714554967

Recebimento: 19/06/2020

Aprovação: 16/09/2020

\section{Q.Code}

\section{Editores-Responsáveis}

Prof. Dr. Enéas de Araújo Arrais Neto, Universidade Federal do Ceará - UFC, Brasil

Prof. Dr. Arno Münster, Universidade de Amiens - Paris, França 